\title{
Emergency Management of Obstructive Colorectal Cancer - A Retrospective Study of Efficacy and Safety in Self-expanding Metallic Stents and Trans-anal Tubes
}

\author{
HIROYUKI INOUE, TOMOHIRO ARITA, YOSHIAKI KURIU, HIROKI SHIMIZU, JUN KIUCHI, \\ YUSUKE YAMAMOTO, HIROTAKA KONISHI, RYO MORIMURA, ATSUSHI SHIOZAKI, HISASHI IKOMA, \\ TAKESHI KUBOTA, HITOSHI FUJIWARA, KAZUMA OKAMOTO and EIGO OTSUJI \\ Division of Digestive Surgery, Department of Surgery, Kyoto Prefectural University of Medicine, Kyoto, Japan
}

\begin{abstract}
Background/Aim: The self-expanding metallic stent (SEMS) has recently been used for obstructive colorectal cancer (OCRC), and reports of its use are increasing. However, the long-term results of OCRC after using SEMS remain unclear. This study investigated the characteristics of SEMS compared to trans-anal tube (TAT) and clarified the long-term results and efficacy of SEMS for OCRC. Patients and Methods: We analyzed 48 patients who required SEMS or TAT for emergent decompression of OCRC and underwent resection for OCRC between 2007 and 2019. The perioperative factors and long-term results in the two groups were evaluated. Results: Patients with OCRC were divided into the SEMS $(n=23)$ and the TAT group ( $n=25)$. No significant differences were seen in background factors, complications and the 5-year overall survival after surgery $(p=0.3500)$ between the two groups. The clinical success of decompression $(p=0.0072)$, oral intake $(p<0.0001)$ and change in serum albumin $(p<0.0001)$ from decompression to surgery were significantly better in the SEMS compares to the TAT group. Conclusion: The long-term outcomes in the SEMS group were not significantly different than in the TAT group, and nutritional status was better in patients with SEMS, suggesting that SEMS is very effective and may be the first-line treatment of OCRC.
\end{abstract}

This article is freely accessible online.

Correspondence to: Tomohiro Arita, MD, Ph.D., Division of Digestive Surgery, Department of Surgery, Kyoto Prefectural University of Medicine 465, Kajii-cho, Kamigyo-ku, Kyoto, Japan. Tel: +81 752515527, Fax: +81 752515522, e-mail: t-art@koto.kpum.ac.jp

Key Words: Self-expanding metallic stents, colorectal cancer, bridge to surgery, long-term outcomes.
Colorectal cancer (CRC) is the third most common malignancy and the fifth leading cause of death worldwide. $\mathrm{CRC}$ is a common cancer with a yearly worldwide incidence of approximately 1,097,000 new cases and 551,000 deaths (1). Intestinal obstruction is one of the common presenting symptoms of CRC. Obstructive colorectal cancer (OCRC) was estimated to occur in $7-16 \%$ of CRC cases and was the main reason for emergency surgery in patients with CRC (2-5).

Emergency surgery for OCRC is usually associated with increased morbidity, mortality, post-operative complications, and stoma creation rate compared to elective surgery (6-8). Stoma creation is permanent in up to $40 \%$ of patients, and significantly reduces the patients' quality of life (QOL) (9, 10). In order to avoid emergency surgery and permanent stoma creations, various types of procedures, such as temporary stoma, trans-anal tube (TAT), and self-expanding metallic stent (SEMS), are used $(11,12)$.

Recently, elective surgery has been selected more frequently than emergency primary tumor resection (ER). SEMS was introduced as a palliative treatment measure for OCRC in patients with incurable disease $(13,14)$ and as a bridge to surgery (BTS) $(15,16)$ in the 1990s. In Japan, SEMS has been generally used for curative OCRC since 2012 .

Some studies reported that SEMS was an effective and safe treatment of OCRC (17-19). On the other hand, others have shown that SEMS exacerbated the lymphovascular invasion caused by the pressure of the cancer tissue, resulting in local recurrence and peritoneum dissemination by perforation at a constant rate $(20,21)$. The effectiveness and safety of SEMS is still controversial, and the oncologic outcomes and long-term results of elective surgery after using SEMS remain unclear.

The aim of the present study was to investigate the clinical characteristics of OCRC and clarify the efficacy and safety of SEMS for OCRC. We also compared the status of use, preoperative conditions, postoperative outcomes, and longterm results of SEMS with TAT for OCRC. 


\section{Patients and Methods}

Patients and data collection. Forty-eight patients undergoing resection for OCRC between January 2007 and December 2019 at our Institution were included in this study. The selection criteria were as follows: 1) histologically confirmed colorectal cancer; 2) acute colonic obstruction and who could not receive any oral intake; 3) required SEMS or TAT for emergent decompression; and 4) underwent resection of the primary tumor. Patients who received palliative colostomy without primary tumor resection, only underwent stent insertion without surgery, or only underwent trans-oral decompression, such as stomach tube or ileus tube insertion, were excluded from this study. Patients who underwent emergency primary tumor resection or temporary stoma construction were also excluded.

All patients provided written informed consents before the operation. This study was approved by the ethics committee of our institution (approval no. ERB-1178-1).

Definition of OCRC and decompression procedure. We defined OCRC (22) as obstruction diagnosed by medical history, physical examination, computed tomography (CT), or colonoscopy in patients with colorectal cancer that was confirmed by histological examination.

The therapeutic strategy for OCRC, such as emergency primary tumor resection or a decompression procedure (SEMS, TAT, or temporary stoma), were decided upon following discussion between the surgeons and the endoscopists. Excluding high risk cases of perforation determined by the surgeons and the endoscopists, emergency primary tumor resection was avoided as far as possible. For patients with lower rectal cancer, TAT was preferred to avoid the risk of SEMS migrating distally and interfering with transection of the distal rectum. Temporary stoma was chosen when neoadjuvant chemotherapy before primary tumor resection was necessary, when guidewire to introduce SEMS or TAT could not be inserted, or when the SEMS or TAT were obstructed. Insertion of SEMS or TAT was carried out by endoscopists.

For SEMS, we used WallFlex ${ }^{\mathrm{TM}}$, HANAROSTENT ${ }^{\circledR}$ Naturfit $^{\mathrm{TM}}$, or Niti-S ${ }^{\mathrm{TM}}$. The WallFlex ${ }^{\mathrm{TM}}$ enteral colonic stent (Boston Scientific Corporation, Marlborough, MA, USA) was 6,9 , or $12 \mathrm{~cm}$ in length, with flare flange/mid-body diameters of either $27 / 22$ or $30 / 25 \mathrm{~mm}$. The HANAROSTENT ${ }^{\circledR}$ Naturfit $^{\mathrm{TM}}$ (Boston Scientific Corporation) was 6,9 , or $12 \mathrm{~cm}$ in length, outer diameters of either 20 or $22 \mathrm{~mm}$. The Niti-S ${ }^{\mathrm{TM}}$ type D enteral colonic stent (TaeWoong Medical Co., Ltd., Gyeonggi-do, Republic of Korea) was 6, 8, 10, or $12 \mathrm{~cm}$ in length and 18 or $22 \mathrm{~mm}$ in diameter. The appropriate SEMS was decided by an endoscopist. For TAT, the scope was removed leaving the guidewire in place, and a Dennis Colorectal Tube (7.3 mm outer diameter and $145 \mathrm{~cm}$ length; Coviden Japan, Tokyo, Japan) was inserted over the wire. The balloon at the tube tip was insufflated with $20-30 \mathrm{ml}$ of water for fixation. The tube was flushed once or twice a day to prevent clogging. Clinical success was defined as correct placement, and resolution of obstruction was evaluated by physical symptoms and X-ray examination. For patients who had undergone successful SEMS and TAT placement, elective surgery was performed about 2 weeks later.

Surgical procedure and pathological evaluation. The primary tumor resection and lymph node dissection were performed based on the Japanese Society for the Cancer of the Colon and Rectum (JSCCR) Guidelines for the Treatment of Colorectal Cancer (23). Resected specimens were assessed by pathologists based on the tumor-node- metastasis $(\mathrm{TNM})\left(8^{\text {th }}\right.$ edition) staging system by the Union for International Cancer Control (UICC) (24). In this study, the definition of right- and left-sided colon lesion was in accord with a previous study (25). The border between the right- and left-sided colon was the proximal two-thirds of the transverse colon.

Follow-up data. After colorectal resection for OCRC, patients were followed up at regular intervals with serum carcinoembryonic antigen (CEA) and cancer antigen (CA) 19-9 every 3 months; CT of the chest, abdomen, and pelvis every 6 months; and colonoscopy every 12 months, according to the JSCCR guidelines. The first follow-up was performed a month after primary tumor resection, then a follow-up was performed every 3 months for up to 3 years and every 6 months thereafter. All patients were followed up until their death or 5 years after primary tumor resection.

After primary tumor resection, adjuvant chemotherapy was recommended for all patients based on the JSCCR guidelines, unless the patient's performance status (PS) was not suitable for systemic chemotherapy or the patients declined chemotherapy. The chemotherapeutic regimens administered were also in line with the JSCCR guidelines. The chemotherapeutic options were mostly oxaliplatin-based regimens or uracil-tegafur with leucoborin.

Statistical analyses. The correlation between the clinicopathological parameters and the decompression procedures was compared using the chi-square test and Mann-Whitney $U$-test. Values are presented as the median (range) and percentage. Overall survival (OS) and recurrence-free survival (RFS) were generated using the KaplanMeier method and differences between groups were assessed with the log-rank test. A $p$-value $<0.05$ was considered significant. Statistical analyses were performed with the software package JMP software version 10 (JMP, Cary, NC, USA).

\section{Results}

Clinical characteristics and distributions in patients with $O C R C$. The clinicopathological characteristics of patients are shown in Table I. Their median age was 72 years (range $=47$ 91 years), with 28 male $(58.3 \%)$ and 20 female patients (41.7\%). The majority of patients (47/48: $97.1 \%)$ had an advanced $\mathrm{T}$ stage (T3/T4) and nearly half of the patients had positive lymph nodes (22/48: 45.8\%) in their primary tumors. Among the patients, $11(22.9 \%)$ primary tumors were located in right-sided colon, 20 (41.7\%) in the leftsided colon, and $17(35.4 \%)$ in the rectum. The median follow-up after primary tumor resection was 35.5 months (range=39 days to 112 months). Patients were classified into two groups: a SEMS group $(n=23)$, and a TAT group $(n=25)$.

Comparison of clinicopathological factors, postoperative outcomes, and long-term results between SEMS and TAT. We investigated the clinical characteristics of patients and the long-term outcomes between the SEMS and TAT groups. Clinicopathological findings of the 48 patients are summarized in Table I. There were no significant differences of background factors, such as age, sex and preoperative tumor marker level, and surgical or postoperative factors, 
Table I. Analysis of clinicopathological factors in the SEMS group and the TAT group.

\begin{tabular}{|c|c|c|c|c|c|}
\hline \multirow[t]{2}{*}{ Variables } & & \multirow[t]{2}{*}{$\mathrm{n}=48$} & \multicolumn{2}{|c|}{ Group } & \multirow[t]{2}{*}{$p$-Value ${ }^{\mathrm{d}}$} \\
\hline & & & SEMS $(n=23)$ & TAT $(n=25)$ & \\
\hline \multirow[t]{3}{*}{ Age, years } & Median (range) & $72(47-91)$ & & & \\
\hline & $<65$ & $14(29.2 \%)$ & $6(26.1 \%)$ & $8(32.0 \%)$ & 0.6520 \\
\hline & $\geq 65$ & $34(70.8 \%)$ & $17(73.9 \%)$ & $17(68.0 \%)$ & \\
\hline \multirow[t]{2}{*}{ Gender } & Male & $28(58.3 \%)$ & $12(52.2 \%)$ & $16(64.0 \%)$ & 0.4060 \\
\hline & Female & $20(41.7 \%)$ & $11(47.8 \%)$ & $9(36.0 \%)$ & \\
\hline \multirow[t]{2}{*}{$\mathrm{CEA}^{\mathrm{a}}(\mathrm{ng} / \mathrm{ml})$} & $<5$ & $19(39.6 \%)$ & $11(47.8 \%)$ & $8(32.0 \%)$ & 0.2619 \\
\hline & $\geq 5$ & $29(60.4 \%)$ & $12(52.2 \%)$ & $17(68.0 \%)$ & \\
\hline \multirow[t]{2}{*}{ CA19-9a (U/ml) } & $<37$ & $39(81.2 \%)$ & $18(78.3 \%)$ & $21(84.0 \%)$ & 0.6108 \\
\hline & $\geq 37$ & $9(18.8 \%)$ & $5(21.7 \%)$ & $4(16.0 \%)$ & \\
\hline \multirow[t]{2}{*}{ Success of decompression ${ }^{b}$} & Yes & $48(88.9 \%)$ & $23(100.0 \%)$ & $25(80.6 \%)$ & $0.0072 *$ \\
\hline & No & $6(11.1 \%)$ & $0(0.0 \%)$ & $6(19.4 \%)$ & \\
\hline \multirow[t]{2}{*}{ Oral intake } & Yes & $18(37.5 \%)$ & $17(73.9 \%)$ & $1(4.0 \%)$ & $<0.0001 *$ \\
\hline & No & $30(62.5 \%)$ & $6(26.1 \%)$ & $24(96.0 \%)$ & \\
\hline Change in the serum albumin & Median (range) & $-0.45(-1.7-+0.7)$ & $-0.15(-1.0-+0.7)$ & $-0.7(-1.7-+0.3)$ & $<0.0001 *$ \\
\hline \multirow[t]{3}{*}{ Location } & Right sided colon & $11(22.9 \%)$ & $5(21.7 \%)$ & $6(24.0 \%)$ & $0.0156^{*}$ \\
\hline & Left sided colon & $20(41.7 \%)$ & $14(60.9 \%)$ & $6(24.0 \%)$ & \\
\hline & Rectum & $17(35.4 \%)$ & $4(17.4 \%)$ & $13(52.0 \%)$ & \\
\hline Tumor size, mm & Median (range) & $60(20-155)$ & $60(20-155)$ & $60(30-146)$ & 0.7405 \\
\hline \multirow[t]{2}{*}{ Vascular invasion ${ }^{\mathrm{c}}$} & Absence & $16(33.3 \%)$ & $9(39.1 \%)$ & $7(28.0 \%)$ & 0.4135 \\
\hline & Presence & $32(66.7 \%)$ & $14(60.9 \%)$ & $18(72.0 \%)$ & \\
\hline \multirow[t]{2}{*}{ Lymphatic invasion ${ }^{\mathrm{c}}$} & Absence & $23(47.9 \%)$ & $10(43.5 \%)$ & $13(52.0 \%)$ & 0.5546 \\
\hline & Presence & $25(52.1 \%)$ & $13(56.5 \%)$ & $12(48.0 \%)$ & \\
\hline \multirow[t]{2}{*}{ pT Stage ${ }^{\mathrm{c}}$} & $\geq 2$ & $1(2.1 \%)$ & $1(4.3 \%)$ & $0(0.0 \%)$ & 0.2215 \\
\hline & $\leq 3$ & $47(97.9 \%)$ & $22(95.7 \%)$ & $25(100.0 \%)$ & \\
\hline \multirow[t]{2}{*}{ pN Stage ${ }^{c}$} & 0 & $26(54.2 \%)$ & $13(56.5 \%)$ & $13(52.0 \%)$ & 0.7534 \\
\hline & $\leq 1$ & $22(45.8 \%)$ & $10(43.5 \%)$ & $12(48.0 \%)$ & \\
\hline \multirow[t]{2}{*}{ pStage $^{\mathrm{c}}$} & $\leq \mathrm{III}$ & $31(64.6 \%)$ & $16(69.6 \%)$ & $15(60.0 \%)$ & 0.4879 \\
\hline & IV & $17(35.4 \%)$ & $7(30.4 \%)$ & $10(40.0 \%)$ & \\
\hline \multirow[t]{2}{*}{ Open or Lap } & Open & $12(25.0 \%)$ & $4(17.4 \%)$ & $8(32.0 \%)$ & 0.2389 \\
\hline & Lap & $36(75.0 \%)$ & $19(82.6 \%)$ & $17(68.0 \%)$ & \\
\hline Bleeding, $g$ & Median (range) & $19.5(0-2835)$ & $0(0-344)$ & $32(0-2835)$ & 0.0986 \\
\hline Operation time, $\min$ & Median (range) & $255(120-634)$ & $254(120-547)$ & $256(150-634)$ & 0.8284 \\
\hline \multirow[t]{2}{*}{ Permanent stoma creation } & No & $36(75.0 \%)$ & $22(95.7 \%)$ & $14(56.0 \%)$ & $0.0007 *$ \\
\hline & Yes & $12(25.0 \%)$ & $1(4.3 \%)$ & $11(44.0 \%)$ & \\
\hline \multirow[t]{2}{*}{ SSI } & No & $42(87.5 \%)$ & $22(95.7 \%)$ & $20(80.0 \%)$ & 0.0873 \\
\hline & Yes & $6(12.5 \%)$ & $1(4.3 \%)$ & $5(20.0 \%)$ & \\
\hline \multirow[t]{2}{*}{ Leakage } & No & $47(97.9 \%)$ & $23(100.0 \%)$ & $24(96.0 \%)$ & 0.2498 \\
\hline & Yes & $1(2.1 \%)$ & $0(0.0 \%)$ & $1(4.0 \%)$ & \\
\hline Postoperative hospital stay, days & Median (range) & $14.5(8-61)$ & $13(8-47)$ & $16(8-61)$ & $0.0184 *$ \\
\hline
\end{tabular}

CEA: Carcinoembryonic antigen; CA19-9: cancer antigen (CA) 19-9; Open: open surgery; Lap: laparoscopic surgery; SSI: surgical site infection;

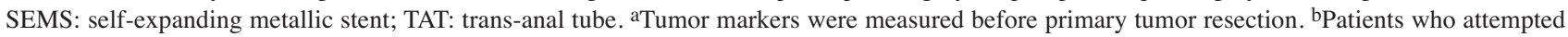
SEMS $(n=23)$ or TAT $(n=31)$ insertion, including successes and failures, ${ }^{c}$ According to the $8^{\text {th }}$ edition of the UICC/TNM staging system, ${ }^{d} p$-values are from chi-squared test or Mann-Whitney $U$-test.

such as the rate of open surgery, bleeding, operation time, SSI, and leakage, between the SEMS and TAT groups. There were also no significant differences of the factors associated with pathological and long-term outcomes, such as pathological stage and lymphovascular invasion between these two groups. No complications related to the insertion of SEMS or TAT were observed. The 5-year OS rates were not significantly different between these two groups (SEMS group $69.5 \%$, TAT group $38.4 \%, p=0.3500$, Figure 1).
Tumors located in the left-sided colon were more frequent in the SEMS group, whereas tumors located in the rectum were more frequent in the TAT group $(p=0.0156)$. The clinical success of decompression rate in the SEMS group was significantly higher than in the TAT group ( $p=0.0072)$. After the insertion of SEMS or TAT, the rate of oral intake in the SEMS group was significantly higher than in the TAT $(p<0.0001)$. The preoperative serum albumin levels in the SEMS group were significantly higher than those in the TAT 


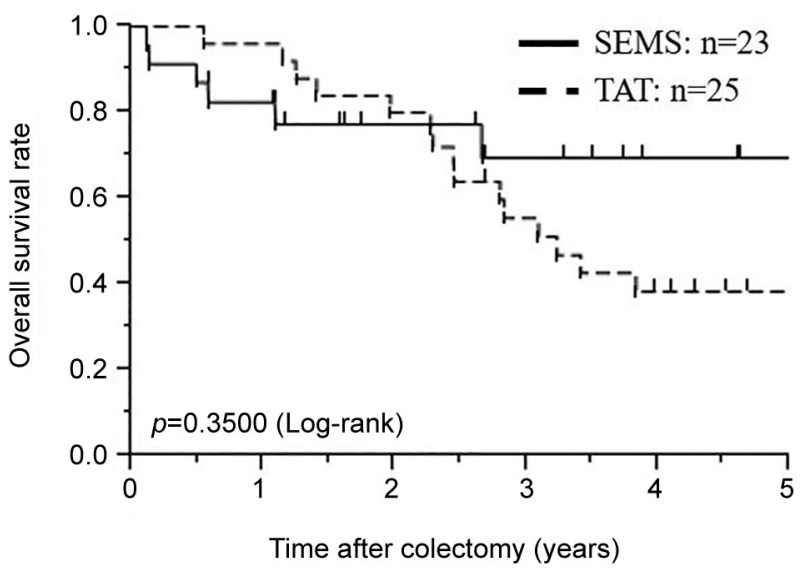

Figure 1. Comparison of overall survival (OS) after curative colectomy for patients between the SEMS group and the TAT group. SEMS: Selfexpanding metallic stent, TAT: trans-anal tube. $p$-Values are from logrank test.

group ( $p=0.0275$, Figure $2 \mathrm{~A})$. The decrease in serum albumin from decompression to surgery was significantly greater in the TAT group than the SEMS group $(p<0.0001$, Figure 2B). The modified Glasgow prognostic score (mGPS) in the SEMS group was significantly lower than that in the TAT group ( $p=0.0325$, Figure $2 \mathrm{C}$ ). As a result, the nutritional status of patients in the SEMS group was better than that in the TAT group before operation.

Comparison of clinicopathological factors, postoperative outcomes, and long-term results between SEMS and TAT in left-sided colorectal cancer patients undergoing RO surgery. When we assessed patients who underwent an R0 operation and patients with a primary tumor in left-sided colon or rectum, the result was similar (Table II). The rate of open surgery, bleeding, operation time, SSI, leakage, and postoperative hospital stay were not significantly different between the two groups (SEMS group: $n=14$, TAT group: $\mathrm{n}=10$ ). The rate of oral intake in the SEMS group was significantly higher than in the TAT group $(p=0.0002)$. The decrease in serum albumin from decompression to surgery was significantly greater in the TAT group than the SEMS group ( $p=0.0049)$. The 5-year OS and RFS rates of the SEMS and TAT groups after primary tumor resection was not significantly different (5-year OS rates: SEMS group 87.5\%, TAT group $68.6 \%, p=0.3240$; 5-year RFS: $61.4 \%, 46.7 \%$, respectively, $p=0.5931$, Figure 3 ).

\section{Discussion}

The efficacy and safety of SEMS for OCRC is controversial (17-21). In the present study, we demonstrated the efficacy and safety of SEMS for OCRC. Moreover, we compared the status of use, preoperative condition, postoperative outcomes, and long-term results between SEMS and TAT for OCRC. This is the first report that investigated preoperative nutritional status and long-term outcomes between SEMS and TAT. Our results suggest that SEMS is an effective treatment for OCRC.

The numerous reports on short-term outcomes (26-28) showed that BTS improved short-term prognosis compared to ER. Therefore, in recent years, BTS using SEMS or TAT has become the mainstream treatment for OCRC. SEMS and TAT after endoscopic decompression converted emergency surgery into elective one-stage surgery. Both SEMS and TAT were effective as a BTS, and associated with reduced morbidity, mortality, complications, and stoma rate compared to emergency surgery (29-31). However, Kurumiya et al. reported that much time is taken to flush the TAT to prevent clogging, and the success of decompression rate was about $80 \%$ (32), which is less than SEMS. In addition, the nutritional status of patients in TAT got worse because they waited for surgery without oral intake. Previous studies showed that insufficient improvement of intestinal condition and nutritional status could develop leakage $(33,34)$. Thus, oral intake before surgery may benefit patients with OCRC.

In the present study, the rate of leakage was not significantly different between the SEMS and TAT groups; however, the success of decompression rate was higher and the nutritional status of patients before primary tumor resection was better in SEMS than in TAT. In addition, patients who received TAT were hospitalized until primary tumor resection, which had an adverse effect on QOL. Moreover, SEMS insertion makes it possible to perform total colonoscopy, which is clinically useful both to diagnose multiple synchronous lesions and to determine the safety margin for resection. Thus, SEMS might be better than TAT in various respects.

Sabbagh et al. (17) reported negative outcomes, including vascular invasion, perineural invasion, and lymph node invasion, associated with SEMS placement. Tung et al. (20) and Sloothaak et al. (21) reported that surgery after SEMS placement for OCRC was associated with a higher risk of local recurrence and peritoneal metastasis. On the other hand, Nakano et al. (35) reported that SEMS insertion allowed patients to undergo surgery under better conditions without causing adverse effects on lymphovascular invasion, and Sato et al. (7) reported that the rate of local recurrence and peritoneal metastasis was not significantly different between SEMS and TAT. These results are controversial. The European Society of Gastrointestinal Endoscopy (ESGE) guidelines reported a success rate of SEMS insertion of about $76.9 \%$ (36). On the other hand, several studies showed that in Japan the success rate of SEMS insertion was very high (92-100\%) $(37,38)$. In addition, The ESGE guidelines showed that the rate of perforation with the use of SEMS ranged from 0 to $12.8 \%$ and which was higher than that of TAT $(17,20,39)$. 

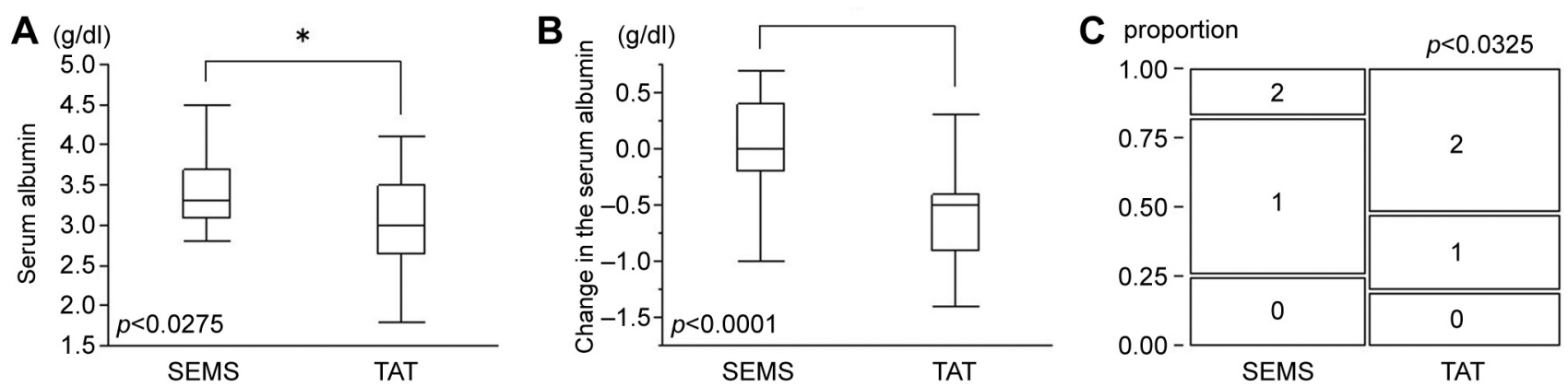

Figure 2. (A) Analysis of preoperative serum albumin level of patients in the SEMS group and the TAT group. (B) Analysis of preoperative change in serum albumin level in the SEMS group and the TAT group. (C) Analysis of preoperative Japanese modified Glasgow prognostic score ( $m G P S$ ) level of patients in the SEMS group and the TAT group. The numbers in the box are mGPS. SEMS: Self-expanding metallic stent, TAT: trans-anal tube. p-Values are from Mann-Whitney U-test.
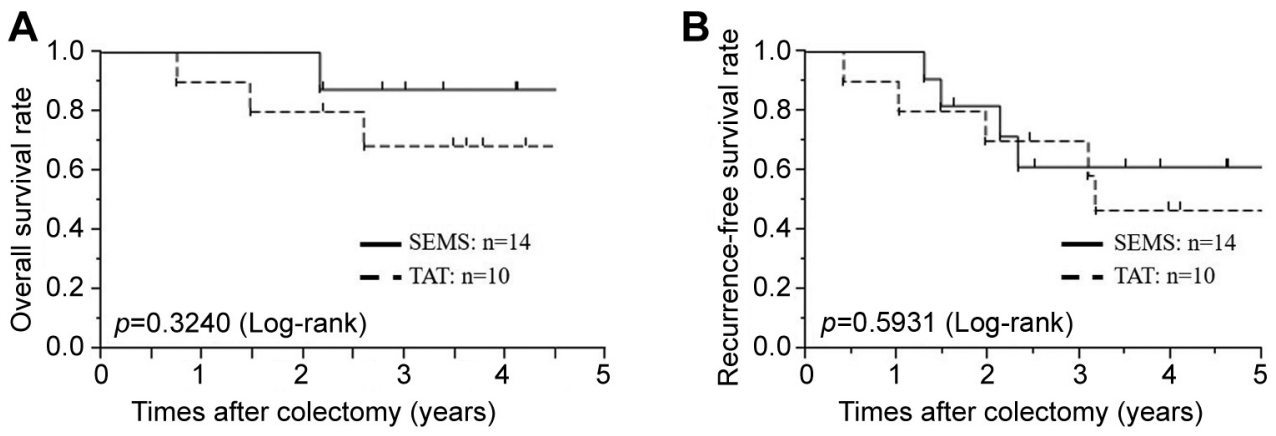

Figure 3. (A) Comparison of overall survival (OS) between the SEMS and TAT group after curative colectomy for patients who received an RO operation and the primary tumor was found in the left-sided colon or rectum. (B) Comparison of recurrence-free survival (RFS) between the SEMS group and the TAT group after curative colectomy for patients who received an RO operation and the primary tumor was found in the left-sided colon or rectum. SEMS: Self-expanding metallic stent, TAT: trans-anal tube. p-Values are from the log-rank test.

Meanwhile, other reports demonstrated that the rate of perforation with the use of SEMS ranged from 2.1 to $4.5 \%$ (40-42) and the rate of perforation in Japan was similarly low $(23,43)$, which was lower than that of TAT. The reported success and perforation rate of SEMS insertion varied by report and were different between the Japanese and the ESGE guidelines. These indicate that the outcomes of placement procedures, which may influence the long-term prognosis, are substantially different between the Japanese and ESGE guidelines, resulting in the above controversial results.

SEMS and TAT are generally considered to have advantages such as avoidance of ER or stoma construction, and increase in the primary resection anastomosis rate. TAT has disadvantages such as the existence of cases of difficult decompression, the complexity of flushing the TAT to prevent clogging and the decrease in patient QOL, whereas SEMS has been reported the potential to worsen long-term prognosis. In the present study, the long-term outcomes, such as 5-year OS and RFS rates and lymphovascular invasion were not significantly different between the SEMS group and the TAT group, which was consistent with a previous study in Japan and reinforces the opinion that SEMS is safe. In addition, SEMS has been shown to improve preoperative nutritional status and may be an effective treatment for OCRC.

This study has several limitations. First, it was a retrospective and non-randomized study with a relatively small sample size from one institution; therefore, the findings have the selection bias and need to be validated in a larger prospective cohort of patients from multiple institutions. Second, this study was not a non-inferiority clinical trial and equivalence trial. Although long-term outcomes were not significantly different between the SEMS group and the TAT group, they were not equal. Third, SEMS was introduced in 2013, whereas most patients in the BTS group received TAT before 2013. The difference in the observation period may have led to the difference in the results between SEMS and TAT.

Despite these limitations, the results of this study may lead to a better understanding of BTS for OCRC. Moreover, SEMS could be an effective and safe treatment for OCRC. A randomized controlled, prospective, multi-institutional study with a big sample size is needed to clarify the superiority of treatment with SEMS compared to TAT. 
Table II. Analysis of clinicopathological factors in the SEMS group and the TAT group for patients who received a curative resection (R0 resection) and the primary tumor was found in the left-side.

\begin{tabular}{|c|c|c|c|c|c|}
\hline \multirow[t]{2}{*}{ Variables } & & \multirow[t]{2}{*}{$\mathrm{n}=24$} & \multicolumn{2}{|c|}{ Group } & \multirow[t]{2}{*}{$p$-Value ${ }^{\mathrm{d}}$} \\
\hline & & & SEMS $(n=14)$ & TAT $(n=10)$ & \\
\hline \multirow[t]{3}{*}{ Age, years } & Median (range) & $71(50-90)$ & & & \\
\hline & $<65$ & $7(29.2 \%)$ & $4(28.6 \%)$ & $3(30.0 \%)$ & 0.9395 \\
\hline & $\geq 65$ & $17(70.8 \%)$ & $10(71.4 \%)$ & $7(70.0 \%)$ & \\
\hline \multirow[t]{2}{*}{ Gender } & Male & $15(62.5 \%)$ & $7(50.0 \%)$ & $8(80.0 \%)$ & 0.1262 \\
\hline & Female & $9(37.5 \%)$ & $7(50.0 \%)$ & $2(20.0 \%)$ & \\
\hline \multirow[t]{2}{*}{$\mathrm{CEA}^{\mathrm{a}}(\mathrm{ng} / \mathrm{ml})$} & $<5$ & $13(54.2 \%)$ & $7(50.0 \%)$ & $6(60.0 \%)$ & 0.6272 \\
\hline & $\geq 5$ & $11(45.8 \%)$ & $7(50.0 \%)$ & $4(40.0 \%)$ & \\
\hline \multirow[t]{2}{*}{ CA19-9a (U/ml) } & $<37$ & $22(91.7 \%)$ & $13(92.9 \%)$ & $9(90.0 \%)$ & 0.8041 \\
\hline & $\geq 37$ & $2(8.3 \%)$ & $1(7.1 \%)$ & $1(10.0 \%)$ & \\
\hline \multirow[t]{2}{*}{ Success of decompression ${ }^{b}$} & Yes & $24(80.0 \%)$ & $14(100.0 \%)$ & $10(62.5 \%)$ & $0.0029^{*}$ \\
\hline & No & $6(20.0 \%)$ & $0(0.0 \%)$ & $6(37.5 \%)$ & \\
\hline \multirow[t]{2}{*}{ Oral intake } & Yes & $9(37.5 \%)$ & $9(64.3 \%)$ & $0(0.0 \%)$ & $0.0002 *$ \\
\hline & No & $15(62.5 \%)$ & $5(35.7 \%)$ & $10(100.0 \%)$ & \\
\hline Change in the serum albumin & Median (range) & $-0.25(-1.4-+0.7)$ & $-0.05(-1.0-+0.7)$ & $-0.8(-1.4--0.1)$ & $0.0049 *$ \\
\hline \multirow[t]{2}{*}{ Location } & Left sided colon & $15(62.5 \%)$ & $12(85.7 \%)$ & $3(30.0 \%)$ & $0.0045^{*}$ \\
\hline & Rectum & $9(37.5 \%)$ & $2(14.3 \%)$ & $7(70.0 \%)$ & \\
\hline Tumor size, mm & Median (range) & $57.5(20-100)$ & $59.5(20-100)$ & $55(30-80)$ & 0.5760 \\
\hline \multirow[t]{2}{*}{ Vascular invasion ${ }^{\mathrm{c}}$} & Absence & $11(45.8 \%)$ & $8(57.1 \%)$ & $3(30.0 \%)$ & 0.1839 \\
\hline & Presence & $13(54.2 \%)$ & $6(42.9 \%)$ & $7(70.0 \%)$ & \\
\hline \multirow[t]{2}{*}{ Lymphatic invasion $^{\mathrm{c}}$} & Absence & $13(54.2 \%)$ & $7(50.0 \%)$ & $6(60.0 \%)$ & 0.6272 \\
\hline & Presence & $11(45.8 \%)$ & $7(50.0 \%)$ & $4(40.0 \%)$ & \\
\hline \multirow[t]{2}{*}{ pT Stage ${ }^{\mathrm{c}}$} & $2 \geq$ & $1(4.2 \%)$ & $1(7.1 \%)$ & $0(0.0 \%)$ & 0.2923 \\
\hline & $3 \leq$ & $23(95.8 \%)$ & $13(92.9 \%)$ & $10(100.0 \%)$ & \\
\hline \multirow[t]{2}{*}{ pN Stage $\mathrm{c}$} & 0 & $15(62.5 \%)$ & $9(64.3 \%)$ & $6(60.0 \%)$ & 0.8309 \\
\hline & $1 \leq$ & $9(37.5 \%)$ & $5(35.7 \%)$ & $4(40.0 \%)$ & \\
\hline \multirow[t]{2}{*}{ pStage ${ }^{\mathrm{c}}$} & $\mathrm{II} / \mathrm{III}$ & $20(83.3 \%)$ & $11(78.6 \%)$ & $9(90.0 \%)$ & 0.4475 \\
\hline & IV & $4(16.7 \%)$ & $3(21.4 \%)$ & $1(10.0 \%)$ & \\
\hline \multirow[t]{2}{*}{ Open or Lap } & Open & $5(20.8 \%)$ & $2(14.3 \%)$ & $3(30.0 \%)$ & 0.3529 \\
\hline & Lap & $19(79.2 \%)$ & $12(85.7 \%)$ & $7(70.0 \%)$ & \\
\hline Bleeding, $\mathrm{g}$ & Median (range) & $0(0-2835)$ & $0(0-344)$ & $60(0-2835)$ & 0.1509 \\
\hline Operation time, $\min$ & Median (range) & $269(173-634)$ & $246.5(173-351)$ & $284(179-634)$ & 0.2782 \\
\hline \multirow[t]{2}{*}{ Permanent stoma creation } & No & $20(83.3 \%)$ & $14(100.0 \%)$ & $6(60.0 \%)$ & $0.0043 *$ \\
\hline & Yes & $4(16.7 \%)$ & $0(0.0 \%)$ & $4(40.0 \%)$ & \\
\hline \multirow[t]{2}{*}{ SSI } & No & $22(91.7 \%)$ & $14(100.0 \%)$ & $8(80.0 \%)$ & 0.0525 \\
\hline & Yes & $2(8.3 \%)$ & $0(0.0 \%)$ & $2(20.0 \%)$ & \\
\hline \multirow[t]{2}{*}{ Leakage } & No & $24(100.0 \%)$ & $14(100.0 \%)$ & $10(100.0 \%)$ & NA \\
\hline & Yes & $0(0.0 \%)$ & $0(0.0 \%)$ & $0(0.0 \%)$ & \\
\hline Postoperative hospital stay, days & Median (range) & $12(8-28)$ & $11(8-23)$ & $14(8-25)$ & 0.2635 \\
\hline
\end{tabular}

CEA: Carcinoembryonic antigen; CA19-9: cancer antigen (CA) 19-9; Open: open surgery; Lap: laparoscopic surgery; SSI: surgical site infection;

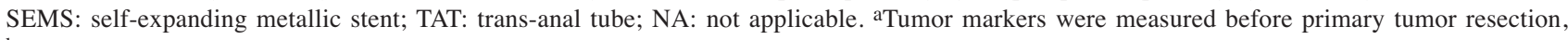
bPatients who received SEMS $(\mathrm{n}=14)$ or TAT $(\mathrm{n}=16)$ insertion, including successes and failures, ${ }^{\mathrm{c}}$ According to the 8 th edition of UICC/TNM staging system, ${ }^{\mathrm{d}} p$-values are from chi-squared test or Mann-Whitney $U$-test.

\section{Conclusion}

Trans-anal decompression, such as SEMS and TAT, may be preferred in terms of avoiding procedures that cause excessive stress on OCRC patients such as emergency surgery and stoma construction. The 5-year OS rates after surgery were not significantly different between the SEMS and TAT groups, and nutritional status and patient's QOL were higher in patients that received SEMS. Thus, SEMS is very effective in the treatment of OCRC and may be a firstline treatment for OCRC.

\section{Conflicts of Interest}

The Authors declare that they have no conflicts of interest and competing interests. 


\section{Authors' Contributions}

Hiroyuki Inoue (HI) and Tomohiro Arita (TA) contributed to the study conception and design. HI acquired data. HI and TA contributed to the analysis and interpretation of data. HI and wrote the manuscript. HI, TA, Yoshiaki Kuriu (YK), Hiroki Shimizu and Jun kiuchi were in charge of the treatment, and all authors determined the treatment plan through preoperative conference. YK and Eigo Otsuji made the critical revision. All Authors have read and approved the manuscript.

\section{References}

1 Bray F, Ferlay J, Soerjomataram I, Siegel RL, Torre LA and Jemal A: Global cancer statistics 2018: GLOBOCAN estimates of incidence and mortality worldwide for 36 cancers in 185 countries. CA Cancer J Clin 68(6): 394-424, 2018. PMID: 30207593. DOI: $10.3322 /$ caac. 21492

2 Jullumstrø E, Wibe A, Lydersen S and Edna TH: Colon cancer incidence, presentation, treatment and outcomes over 25 years Colorectal Dis 13(5): 512-518, 2011. PMID: 20128833. DOI: 10.1111/j.1463-1318.2010.02191.x

3 Atsushi I, Mitsuyoshi O, Kazuya Y, Syuhei K, Noriyuki K, Masashi M, Akira W, Kentaro S, Nobuyuki K, Natsuko S, Jun W, Yasushi I, Chikara K and Itaru E: Long-term outcomes and prognostic factors of patients with obstructive colorectal cancer: A multicenter retrospective cohort study. World J Gastroenterol 22(22): 5237-5245, 2016. PMID: 27298566. DOI: 10.3748/wjg.v22.i22.5237

4 Winner M, Mooney SJ, Hershman DL, Feingold DL, Allendorf JD, Wright JD and Neugut AI: Incidence and predictors of bowel obstruction in elderly patients with stage IV colon cancer: a population-based cohort study. JAMA Surg 148(8): 715-722, 2013. PMID: 23740130. DOI: 10.1001/jamasurg.2013.1

5 Cheynel N, Cortet M, Lepage C, Benoit L, Faivre J and Bouvier AM: Trends in frequency and management of obstructing colorectal cancers in a well-defined population. Dis Colon Rectum 50(10): 1568-1575, 2007. PMID: 17687610. DOI: 10.1007/ s10350-007-9007-4

6 Sjo OH, Larsen S, Lunde OC and Nesbakken A: Short term outcome after emergency and elective surgery for colon cancer. Colorectal Dis 11(7): 733-739, 2009. PMID: 18624817. DOI: 10.1111/j.1463-1318.2008.01613.x

7 Sato R, Oikawa M, Kakita T, Okada T, Oyama A, Abe T, Yazawa T, Tsuchiya H, Akazawa N, Ohira T, Harada Y, Tanaka M, Okano $\mathrm{H}$, Ito $\mathrm{K}$ and Tsuchiya $\mathrm{T}$ : Comparison of the long-term outcomes of the self-expandable metallic stent and transanal decompression tube for obstructive colorectal cancer. Ann Gastroenterol Surg 3(2): 209-216, 2019. PMID: 30923791. DOI: 10.1002/ags3.12235

8 Zhang Y, Shi J, Shi B, Song CY, Xie WF and Chen YX: Selfexpanding metallic stent as a bridge to surgery versus emergency surgery for obstructive colorectal cancer: a meta-analysis. Surg Endosc 26(1): 110-119, 2012. PMID: 21789642. DOI: 10.1007/ s00464-011-1835-6

9 De Ceglie A, Filiberti R, Baron TH, Ceppi M and Conio M: A meta-analysis of endoscopic stenting as bridge to surgery versus emergency surgery for left-sided colorectal cancer obstruction. Crit Rev Oncol Hematol 88(2): 387-403, 2013. PMID: 23845505. DOI: 10.1016/j.critrevonc.2013.06.006

10 Barillari P, Aurello P, De Angelis R, Valabrega S, Ramacciato G, D'Angelo F and Fegiz G: Management and survival of patients affected with obstructive colorectal cancer. Int Surg 77(4): 251255, 1992. PMID: 1335999.

11 Öistämö E, Hjern F, Blomqvist L, Falkén Y, Pekkari K and Abraham-Nordling M: Emergency management with resection versus proximal stoma or stent treatment and planned resection in malignant left-sided colon obstruction. World J Surg Oncol 14(1): 232, 2016. PMID: 27577887. DOI: 10.1186/s12957-016-0994-2

12 Kagami S, Funahashi K, Ushigome M, Koike J, Kaneko T, Koda T, Kurihara A, Nagashima Y, Yoshino Y, Goto M, Mikami T and Chino K: Comparative study between colonic metallic stent and anal tube decompression for Japanese patients with left-sided malignant large bowel obstruction. World J Surg Oncol 16(1): 210, 2018. PMID: 30333034. DOI: 10.1186/s12957-018-1509-0

13 Itabashi M, Hamano K, Kameoka S and Asahina K: Selfexpanding stainless steel stent application in rectosigmoid stricture. Dis Colon Rectum 36(5): 508-511, 1993. PMID: 8482172. DOI: $10.1007 / \mathrm{BF} 02050019$

14 Dohmoto M, Hünerbein M and Schlag PM: Application of rectal stents for palliation of obstructing rectosigmoid cancer. Surg Endosc 11(7): 758-761, 1997. PMID: 9214327. DOI: 10.1007/ s004649900444

15 Tejero E, Mainar A, Fernández L, Tobío R and De Gregorio MA: New procedure for the treatment of colorectal neoplastic obstructions. Dis Colon Rectum 37(11): 1158-1159, 1994. PMID: 7956588. DOI: 10.1007/BF02049822

16 Saida Y, Sumiyama Y, Nagao J and Takase M: Stent endoprosthesis for obstructing colorectal cancers. Dis Colon Rectum 39(5): 552555, 1996. PMID: 8620807. DOI: 10.1007/BF02058710

17 Sabbagh C, Chatelain D, Trouillet N, Mauvais F, Bendjaballah S, Browet F and Regimbeau JM: Does use of a metallic colon stent as a bridge to surgery modify the pathology data in patients with colonic obstruction? A case-matched study. Surg Endosc 27(10): 3622-3631, 2013. PMID: 23572218. DOI: 10.1007/s00464-013-2934-3

18 Guo MG, Feng Y, Zheng Q, Di JZ, Wang Y, Fan YB and Huang $\mathrm{XY}$ : Comparison of self-expanding metal stents and urgent surgery for left-sided malignant colonic obstruction in elderly patients. Dig Dis Sci 56(9): 2706-2710, 2011. PMID: 21442324. DOI: $10.1007 / \mathrm{s} 10620-011-1648-4$

19 Huang X, Lv B, Zhang S and Meng L: Preoperative colonic stents versus emergency surgery for acute left-sided malignant colonic obstruction: a meta-analysis. J Gastrointest Surg 18(3): 584-591, 2014. PMID: 24170606. DOI: 10.1007/s11605-013-2344-9

20 Tung KL, Cheung HY, Ng LW, Chung CC and Li MK: Endolaparoscopic approach versus conventional open surgery in the treatment of obstructing left-sided colon cancer: long-term follow-up of a randomized trial. Asian J Endosc Surg 6(2): 7881, 2013. PMID: 23601995. DOI: 10.1111/ases.12030

21 Sloothaak DA, van den Berg MW, Dijkgraaf MG, Fockens P, Tanis PJ, van Hooft JE, Bemelman WA and collaborative Dutch Stent-In study group: Oncological outcome of malignant colonic obstruction in the Dutch Stent-In 2 trial. Br J Surg 101(13): 1751-1757, 2014. PMID: 25298250. DOI: 10.1002/bjs.9645

22 Veld JV, Wisselink DD, Amelung FJ, Consten ECJ, de Wilt JHW, de Hingh I, Bemelman WA, van Hooft JE, Tanis PJ and Dutch Snapshot Research Group: Synchronous and metachronous peritoneal metastases in patients with left-sided obstructive colon cancer. Ann Surg Oncol 27(8): 2762-2773, 2020. PMID: 32170481. DOI: 10.1245/s10434-020-08327-7

23 Hashiguchi Y, Muro K, Saito Y, Ito Y, Ajioka Y, Hamaguchi T, Hasegawa K, Hotta K, Ishida H, Ishiguro M, Ishihara S, Kanemitsu Y, Kinugasa Y, Murofushi K, Nakajima TE, Oka S, Tanaka T, 
Taniguchi H, Tsuji A, Uehara K, Ueno H, Yamanaka T, Yamazaki K, Yoshida M, Yoshino T, Itabashi M, Sakamaki K, Sano K, Shimada Y, Tanaka S, Uetake H, Yamaguchi S, Yamaguchi N, Kobayashi H, Matsuda K, Kotake K, Sugihara K and Japanese Society for Cancer of the Colon and Rectum: Japanese Society for Cancer of the Colon and Rectum (JSCCR) guidelines 2019 for the treatment of colorectal cancer. Int J Clin Oncol 25(1): 1-42, 2020. PMID: 31203527. DOI: 10.1007/s10147-019-01485-z

24 Brierley JD, Gospodarowicz MK and Wittekind C: TNM classification of malignant tumors 8th edition. Wiley, 2017.

25 Imperial R, Ahmed Z, Toor OM, Erdoğan C, Khaliq A, Case P, Case J, Kennedy K, Cummings LS, Melton N, Raza S, Diri B, Mohammad R, El-Rayes B, Pluard T, Hussain A, Subramanian $\mathrm{J}$ and Masood A: Comparative proteogenomic analysis of rightsided colon cancer, left-sided colon cancer and rectal cancer reveals distinct mutational profiles. Mol Cancer 17(1): 177, 2018. PMID: 30577807. DOI: 10.1186/s12943-018-0923-9

26 Yang SY, Park YY, Han YD, Cho MS, Hur H, Min BS, Lee KY and Kim NK: Oncologic outcomes of self-expandable metallic stent as a bridge to surgery and safety and feasibility of minimally invasive surgery for acute malignant colonic obstruction. Ann Surg Oncol 26(9): 2787-2796, 2019. PMID: 30989498. DOI: 10.1245/s10434-019-07346-3

27 Amelung FJ, Borstlap WAA, Consten ECJ, Veld JV, van Halsema EE, Bemelman WA, Siersema PD, Ter Borg F, van Hooft JE, Tanis PJ and Dutch Snapshot Research Group: Propensity scorematched analysis of oncological outcome between stent as bridge to surgery and emergency resection in patients with malignant left-sided colonic obstruction. Br J Surg 106(8): 1075-1086, 2019. PMID: 31074507 . DOI: 10.1002/bjs. 11172

28 Yagawa Y, Kudo SE, Miyachi H, Mori Y, Misawa M, Sato Y, Kudo K, Ishigaki T, Ichimasa K, Kudo T, Hayashi T, Wakamura $\mathrm{K}$, Baba T and Ishida F: Short- and long-term outcomes of selfexpanding metallic stent placement $v s$. emergency surgery for malignant colorectal obstruction. Mol Clin Oncol 14(4): 63, 2021. PMID: 33680454. DOI: 10.3892/mco.2021.2225

29 Zhang N, Zhou ZL and Xie JL: Application of transanal ileus tube in acute obstructive left-sided colorectal cancer. Int J Clin Exp Med 8(8): 14024-14029, 2015. PMID: 26550362.

30 Arezzo A, Passera R, Lo Secco G, Verra M, Bonino MA, Targarona E and Morino M: Stent as bridge to surgery for leftsided malignant colonic obstruction reduces adverse events and stoma rate compared with emergency surgery: results of a systematic review and meta-analysis of randomized controlled trials. Gastrointest Endosc 86(3): 416-426, 2017. PMID: 28392363. DOI: $10.1016 /$ j.gie.2017.03.1542

31 Allievi N, Ceresoli M, Fugazzola P, Montori G, Coccolini F and Ansaloni L: Endoscopic Stenting as Bridge to Surgery versus Emergency Resection for Left-Sided Malignant Colorectal Obstruction: An Updated Meta-Analysis. Int J Surg Oncol 2017: 2863272, 2017. PMID: 28761765. DOI: $10.1155 / 2017 / 2863272$

32 Kurumiya Y, Terasaki M, Asaba Y, Shingu Y and Natsume S: Use of a tube for immediate retrograde decompression of the ileus from obstruction colorectal cancer: Long-term benefits (in Japanese). J Jpn Soc Abdom Emerg Med 25: 13-19, 2005. DOI: $10.11231 /$ jaem 1993.25 .13

33 Cui J, Zhang JL, Wang S, Sun ZQ and Jiang XL: A preliminary study of stenting followed by laparoscopic surgery for obstructing left-sided colon cancer. Zhonghua Wei Chang Wai Ke Za Zhi 14(1): 40-43, 2011. PMID: 21271379.
34 Lee GJ, Kim HJ, Baek JH, Lee WS and Kwon KA: Comparison of short-term outcomes after elective surgery following endoscopic stent insertion and emergency surgery for obstructive colorectal cancer. Int J Surg 11(6): 442-446, 2013. PMID: 23639803. DOI: 10.1016/j.ijsu.2013.04.010

35 Nakano Y, Terashima H, Hiyama K, Sumi Y, Furukawa K, Imamura F, Kamiga M, Hiroshima Y, Mamiya T and Horiguchi $\mathrm{H}$ : Colorectal stenting for obstructive colorectal cancer as a bridge to surgery: evaluations of short-term benefits. The Japanese Journal of Gastroenterological Surgery 49(9): 834-841, 2019. DOI: $10.5833 /$ jjgs.2015.0199

36 van Hooft JE, van Halsema EE, Vanbiervliet G, Beets-Tan RG, DeWitt JM, Donnellan F, Dumonceau JM, Glynne-Jones RG, Hassan C, Jiménez-Perez J, Meisner S, Muthusamy VR, Parker MC, Regimbeau JM, Sabbagh C, Sagar J, Tanis PJ, Vandervoort J, Webster GJ, Manes G, Barthet MA, Repici A and European Society of Gastrointestinal Endoscopy (ESGE): Self-expandable metal stents for obstructing colonic and extracolonic cancer: European Society of Gastrointestinal Endoscopy (ESGE) Clinical Guideline. Gastrointest Endose 80(5): 747-61.e1-75, 2014. PMID: 25436393. DOI: 10.1016/j.gie.2014.09.018

37 Otsuji A, Saida Y, Enomoto T, Takabayashi K, Nakamura Y, Katagiri M, Nagao S, Watanabe R, Dotai K, Nagaoka Y, Nagao $\mathrm{J}$ and Kusachi S: Feasibility of colorectal obstruction scoring system (CROSS) in colonic stent cases. Progress of Digestive Endoscopy 82(1): 68-71, 2021. DOI: 10.11641/pde.82.1_68

38 Saida Y, Sumiyama Y, Nagao J, Nakamura Y, Nakamura Y, Enomoto T, Katagiri M and Kusachi S: Self-expandable metallic stent for inoperative malignant colorectal stricture: A review of 77 Japanese case reports and 17 patients treated at Ohashi Medical Center. Nippon Daicho Komonbyo Gakkai Zasshi 59(1): 47-53, 2020. DOI: 10.3862/jcoloproctology.59.47

39 Alcántara M, Serra-Aracil X, Falcó J, Mora L, Bombardó J and Navarro S: Prospective, controlled, randomized study of intraoperative colonic lavage versus stent placement in obstructive left-sided colonic cancer. World J Surg 35(8): 1904-1910, 2011. PMID: 21559998. DOI: 10.1007/s00268-011-1139-y

40 Sebastian S, Johnston S, Geoghegan T, Torreggiani W and Buckley M: Pooled analysis of the efficacy and safety of selfexpanding metal stenting in malignant colorectal obstruction. Am J Gastroenterol 99(10): 2051-2057, 2004. PMID: 15447772. DOI: $10.1111 / \mathrm{j} .1572-0241.2004 .40017 . x$

41 Watt AM, Faragher IG, Griffin TT, Rieger NA and Maddern GJ: Self-expanding metallic stents for relieving malignant colorectal obstruction: a systematic review. Ann Surg 246(1): 24-30, 2007. PMID: 17592286. DOI: 10.1097/01 sla.0000261124.72687.72

42 Khot UP, Lang AW, Murali K and Parker MC: Systematic review of the efficacy and safety of colorectal stents. Br J Surg 89(9): 1096-1102, 2002. PMID: 12190673. DOI: 10.1046/ j.1365-2168.2002.02148.x

43 Matsuda A, Miyashita M, Matsumoto S, Sakurazawa N, Takahashi G, Matsutani T, Yamada M and Uchida E: Comparison between metallic stent and transanal decompression tube for malignant large-bowel obstruction. J Surg Res 205(2): 474-481, 2016. PMID: 27664898. DOI: 10.1016/j.jss.2016.04.055

Received April 21, 2021

Revised May 13, 2021

Accepted May 20, 2021 